\title{
Key Oxidation Parameters that Influence Photo-Induced Properties and Applications of Anodic Titanium Oxides
}

\author{
Valerio Piazza, ${ }^{\text {a,b }}$ Anca Mazare,,${ }^{\mathrm{b}, *}$ Maria Vittoria Diamanti, ${ }^{a}$ MariaPia Pedeferri, ${ }^{a}$ \\ and Patrik Schmuki $\mathbf{i}^{\mathrm{b}, * *, \mathbf{z}}$
}

\author{
a Politecnico di Milano, Department of Chemistry, Materials and Chemical Engineering "Giulio Natta", \\ 20131 Milan, Italy \\ ${ }^{b}$ Department of Materials Science WW4-LKO, University of Erlangen-Nuremberg, 91058 Erlangen, Germany
}

\begin{abstract}
In the present work we investigate compact anodic oxides formed on titanium by a broad range of anodizing parameters (electrolyte, applied voltage, substrate pre-treatment) and their influence on the performance of such oxides in photocurrent response and photocatalytic properties (photodegradation of AO7). In general, crystallinity and ion inclusion from the electrolyte are crucial. As-grown compact layers of partial crystallinity show increased efficiencies in both applications; interestingly, phosphate ions have a detrimental effect, whereas sulfate ions do not. After thermal annealing (crystallization) the photoresponse significantly increases: except for a crystallization of the anodic layer, annealing causes a rutile oxide layer growth at the oxide/metal interface - this is found to additionally affect the photoresponse. Results overall demonstrate that higher anodization voltage, exclusion of phosphates from the electrolyte, substrate pre-treatment and annealing are of major importance for achieving an enhanced photoresponse on compact anodic layers.

(C) The Author(s) 2015. Published by ECS. This is an open access article distributed under the terms of the Creative Commons Attribution Non-Commercial No Derivatives 4.0 License (CC BY-NC-ND, http://creativecommons.org/licenses/by-nc-nd/4.0/), which permits non-commercial reuse, distribution, and reproduction in any medium, provided the original work is not changed in any way and is properly cited. For permission for commercial reuse, please email: oa@electrochem.org. [DOI: 10.1149/2.0891602jes] All rights reserved.
\end{abstract}

Manuscript submitted October 15, 2015; revised manuscript received November 19, 2015. Published December 1, 2015.

Anodic oxidation of Ti has been widely studied for the formation of thin compact layers, from 10 to a few hundred nm thick. ${ }^{1-4}$ Depending on the anodic oxidation conditions, growth kinetics can be controlled leading to thinner or thicker layers and in specific conditions oxide crystallization may also occur - for an overview see Vanhumbeeck and Proost ${ }^{5}$ or Diamanti et al. ${ }^{4,6}$ Briefly:

1. the most commonly used electrolytes for $\mathrm{Ti}$ are phosphoric and sulfuric acids (different degrees of dilution), ammonium sulfate and other inorganic salts;

2. use of low voltages (1-130 V) leads to a smooth, amorphous oxide 3-200 nm thick while high potentials (100-250 V) combined with high current densities are parameters used in anodic spark deposition (ASD), where the oxide thickness can be from few to hundreds of $\mu \mathrm{m}$.

Due to the establishment of an electric arc, oxide layers grown by ASD have surface features with a glassy appearance and show the presence of holes where each arc was generated. The process locally melts the oxide, allowing ions present in the electrolyte to be incorporated in the oxide. ${ }^{7,8}$

By anodic oxidation under specific conditions (fluoride containing electrolytes), nanostructured electrodes with one dimensional architectures (nanopores, nanotubes) can also be obtained - these features generally lead to enhanced photoelectrochemical properties (higher surface-to-volume ratio, and directional shape). ${ }^{9-11}$ Overall, anodic oxidation enables control over the morphology, thickness, chemical and structural composition of the growing oxide layer through the used electrochemical parameters. ${ }^{3,4,9,12}$

One of the key features of $\mathrm{TiO}_{2}$ is its use as semiconductor material in photoelectrochemical reactions for the conversion of solar energy into electrical and chemical energy ${ }^{9,11,13,14}$ that can be used e.g. for self-cleaning, ${ }^{15,16}$ pollutant degradation, ${ }^{17}$ dye-sensitized solarcells ${ }^{14}$ and so on. Compared to other semiconductive materials, $\mathrm{TiO}_{2}$ (anatase) has a very high chemical stability, a bandgap of $3.2 \mathrm{eV}$ and possesses suitable band edge positions for reactions with an aqueous environment. For $\mathrm{TiO}_{2}$, the photoefficiency generally depends on crystallinity, with the presence of either anatase, or rutile, or a combination

\footnotetext{
*Electrochemical Society Active Member.

**Electrochemical Society Fellow.

${ }^{z}$ E-mail: schmuki@ww.uni-erlangen.de
}

of the two. For compact layers, as a function of anodic oxidation conditions the crystallinity can be either: a) locally induced by using a high voltage (ASD), leading to anatase $\mathrm{TiO}_{2}$ nanocrystals into an amorphous oxide; ${ }^{18-24}$ or b) induced by further thermal annealing at temperatures ranging from $350^{\circ} \mathrm{C}$ to $650^{\circ} \mathrm{C}$, when the amorphous/partially crystalline oxides are completely converted to crystalline ones. ${ }^{9,24}$ As previously mentioned, high voltage anodic oxidation techniques lead to specific surface features with sub-micrometric porosity and it is characterized by the appearance of craters due to the dielectric breakdown of the anodic films during oxide formation. ${ }^{20,22,24}$

There is an extensive amount of research focused on tuning morphology, crystallinity and chemical composition of anodic compact layers, $, 3,23-26$ as well as on their photoinduced properties as photoelectrochemical water splitting and photocurrent production ${ }^{27-31}$ or photodegradation of organic dyes (acid-orange $7-\mathrm{AO} 7$, methylene blue - ME, Rhodamine B - RhB, etc.). ${ }^{32-38}$ Nevertheless, an overview of the key parameters affecting photoresponse of compact layers is not straightforward, due to the large range of different anodizing conditions reported (i.e. electrolyte, potentiostatic or galvanostatic mode, sample pre-treatment and many more).

Therefore, in the present work we examine and establish the key parameters of compact layers that enhance photoinduced properties, which are examined in terms of photocurrent response and photodegradation of AO7. In this respect, we investigate the applied potential, electrolyte composition, substrate pre-treatment (as delivered or polishing), incorporation of ions from electrolyte (sulfate or phosphate ions) and crystallinity of annealed layers (presence of anatase or rutile).

\section{Experimental}

Oxides production.- Anodic oxidation was performed on $\mathrm{Ti}$ sheets (99.6\% purity, Advent Materials, UK) $0.1 \mathrm{~mm}$ thick and 2 $\mathrm{mm}$ thick (for substrate pre-treated samples). The first set of samples was prepared in $1 \mathrm{M} \mathrm{H}_{2} \mathrm{SO}_{4}$ and $1 \mathrm{M} \mathrm{H}_{3} \mathrm{PO}_{4}$ at different voltages, with and without grinding and polishing treatment on the metallic substrate (grinding with $\mathrm{SiC}$ paper, 4000 grit followed by polishing with Mastermet: $\mathrm{H}_{2} \mathrm{O}_{2}$ volume ratio of $2: 1$ ) - as indicated in Table I. All the substrates were washed in ethanol, rinsed with water and dried in a nitrogen stream before anodizing. Anodic oxidation was carried out in O-ring cell, exposing $1 \mathrm{~cm}^{2}$ of the Ti working electrode to the electrolyte in a two electrode setup with a Pt cathode, in 
Table I. Anodic conditions for growing compact oxide layers.

\begin{tabular}{cccc} 
Name & Electrolyte & Substrate pre-treatment & Applied voltage $\left(\mathrm{U}_{\text {fin }}\right)$ \\
\hline S1 & $1 \mathrm{M} \mathrm{H}_{2} \mathrm{SO}_{4}$ & - & 20 \\
S2 & & - & 50 \\
S3 & & - & 90 \\
S4 & & Mechanical polishing & 50 \\
S5 & & Mechanical polishing & 90 \\
P1 & $1 \mathrm{M} \mathrm{H}_{3} \mathrm{PO}_{4}$ & - & 20 \\
P2 & & - & 50 \\
P3 & & - & 90 \\
P4 & & Mechanical polishing & 50 \\
P5 & & Mechanical polishing & 90
\end{tabular}

potentiodynamic mode (potential ramp $100 \mathrm{mV} / \mathrm{s}$ ) followed by potentiostatic step at the final voltage $U_{\text {fin }}$ for 15 minutes. $I-t$ curves were recorded during the process. After anodizing, samples were rinsed with water and dried in a nitrogen flow.

Oxides structure and composition.- To characterize the structures, a field emission scanning electron microscope (FE-SEM Hitachi 4800) was used for the morphological analysis of the oxide layers. The color of samples was analyzed by a Minolta CM-2600d spectrophotometer, and values were elaborated by applying the CIELAB system, obtaining reflectance curves: this method allowed the evaluation of the oxide layer thickness by applying Bragg's law and Snell's law, as described in previous works. ${ }^{39}$ Chemical composition was measured by X-ray photoelectron spectroscopy (XPS, Physical Electronics 5600) using AlK $\alpha$ monochromized radiation - peaks were calibrated with $\mathrm{C} 1 \mathrm{~s}$ peak at $284.8 \mathrm{eV}$ and fitting of the peaks was performed in Multipak software. The crystal structure was investigated by X-ray diffraction analysis (XRD, X'pert Philips PMD with a Panalytical $X$ 'celerator detector) using graphite-monochromatized $\mathrm{CuK} \alpha$ radiation $(\lambda=1.54056 \AA)$.

In order to further investigate the effect of crystallinity on compact anodic oxides properties, another set of similar samples was produced and annealing was carried out in Jipelec JetFirst 100 RTA at $450^{\circ} \mathrm{C}$ for $1 \mathrm{~h}$, with a heating and cooling rate of $30^{\circ} \mathrm{C} / \mathrm{min}$.

Oxides photoactivity. - Functional characterization of the oxides included the evaluation of both photocurrent production and dye degradation efficiency. Photocurrents were measured under illumination with an ORIEL UV/Vis monochromatic lamp, and samples were immersed in $0.1 \mathrm{M} \mathrm{Na}_{2} \mathrm{SO}_{4}$ electrolyte in a three-electrode setup ( $\mathrm{Pt}$ as counter electrode, $\mathrm{Ag} / \mathrm{AgCl}$ in $3 \mathrm{M} \mathrm{KCl}$ solution as reference electrode). An external potential of $0.5 \mathrm{~V}$ was applied by means of a Jaissle IMP 88 PC power source and a dark-light-dark profile (10 s-20 s-10 s) was set. Photodegradation efficiency was tested under monochromatic illumination at $325 \mathrm{~nm}$ by means of a He-Cd Kimmon IK3552R-G LASER with a measured power density of $60 \mathrm{mWcm}^{-2}$. Samples were immersed in $2.5 \times 10^{-5} \mathrm{M}$ solution of AO7 (Acid Orange 7 , $\mathrm{C}_{16} \mathrm{H}_{11} \mathrm{~N}_{2} \mathrm{NaO}_{4} \mathrm{~S}$, molecular weight: $350.32 \mathrm{~g} / \mathrm{mol}$, Sigma Aldrich), with magnetic stirring at $300 \mathrm{~s}^{-1}$ : dye concentration was measured every 20 minutes by a UV/Vis Perkin Elmer Lambda XLS+ machine, and evaluated by the percent variation of intensity of the absorbance peak at $485 \mathrm{~nm}$.

\section{Results and Discussion}

Oxides production and morphology. - To investigate the difference of anodizing conditions on the growth and morphology of compact oxides, anodic oxidation was performed in $1 \mathrm{M} \mathrm{H}_{2} \mathrm{SO}_{4}$ or $1 \mathrm{M}$ $\mathrm{H}_{3} \mathrm{PO}_{4}$ electrolyte; different voltages were evaluated: 20,50 and 90 $\mathrm{V}: 1 \mathrm{M} \mathrm{H}_{2} \mathrm{SO}_{4}(\mathrm{~S} 1-20 \mathrm{~V}, \mathrm{~S} 2-50 \mathrm{~V}, \mathrm{~S} 3-90 \mathrm{~V})$ or $1 \mathrm{M} \mathrm{H}_{3} \mathrm{PO}_{4}$ $(\mathrm{P} 1-20 \mathrm{~V}, \mathrm{P} 2-50 \mathrm{~V}, \mathrm{P} 3-90 \mathrm{~V})$. All compact oxides were grown under these conditions on the as delivered foil. A preliminary analysis also took in consideration sulfate and phosphate salts with same molarity, $1 \mathrm{M}\left(\mathrm{NH}_{4}\right)_{2} \mathrm{SO}_{4}$ and $1 \mathrm{M} \mathrm{NH}_{4} \mathrm{H}_{2} \mathrm{PO}_{4}$ : yet, lower uniformity of anodizing was obtained as compared with similar layers obtained in acid solution, therefore neutral solutions were discarded (results not shown).

When anodizing under above conditions, Ti foil results macroscopically in a compact oxide morphology, except for when the oxidation process is performed at $90 \mathrm{~V}$ in $1 \mathrm{M} \mathrm{H}_{2} \mathrm{SO}_{4}$ electrolyte (S3) - see S3 in Fig. 1a (top-view SEM images of layers grown at $20 \mathrm{~V}, \mathrm{~S} 1$ and P1, are not shown). The occurrence of this specific porous morphology observed for S3 is related to dielectric breakdown which is characterized by current spikes in the $I-t$ curves registered during oxide growth. The current spikes are related to a sudden release of electric energy in the form of sparks (Fig. 1b) ${ }^{24,26}$ i.e. anodic spark deposition (ASD) conditions are established. Except for samples showing dielectric breakdown, $I-t$ curves registered during anodizing in sulfuric medium appear coherent with literature. ${ }^{40}$

Further, the titanium substrate was subjected to a surface pretreatment, grinding and polishing (referred to as mechanical polishing - pol.), and anodic oxidation was performed at $50 \mathrm{~V}$ and $90 \mathrm{~V}$ in $1 \mathrm{M}$ $\mathrm{H}_{2} \mathrm{SO}_{4}$ (S4 and S5) or $1 \mathrm{M} \mathrm{H}_{3} \mathrm{PO}_{4}$ (P4 and P5), respectively. It has to be pointed out that the substrate pre-treatment ensures the removal of the pre-existing native oxide layer and reduces the breakdown effect as the breakdown spot density is visibly lower in SEM images (see Fig. 1a S5 compared to S3). This is further confirmed by the less intense current spikes in the $I-t$ curve of the S5 sample. Additionally, the reported curves for polished substrates (see Figs. 1b and 1d) show clearly higher currents in the first anodizing period when ASD has not yet started; this can be due to the absence of a resistive native oxide layer and to a slight shift in the breakdown potential $\left(\mathrm{E}_{\mathrm{b}}\right)$ (the shift may be related to the grain orientation of the substrate). ${ }^{18,41}$ In fact, current spikes are also detected for sample P5 (90 V on polished Ti) but no breakdown occurs in the system until more than $60 \mathrm{~V}$ are applied, and even above this threshold the spikes have very low intensity. Thus, this may suggest that actual breakdown has not been fully achieved and it is coherent with the breakdown potential values reported in literature. ${ }^{42,43}$ On the other hand, surface morphology still presents craters typical of ASD hence pointing out that internal stresses arising during oxide growth at high voltage are the main cause for the local cracking and regrowth of $\mathrm{TiO}_{2}$ related to the low intensity spikes. Overall, for anodic oxides grown in phosphoric medium, no breakdown behavior has been observed even at $90 \mathrm{~V}$, probably due to the higher breakdown voltage reported for this electrolyte in literature. ${ }^{24}$

Oxides structure and composition.- As a consequence of the differences observed in the anodizing process, significant variations are observed in the crystallography of compact oxides anodized at higher voltages. In fact, no crystalline oxide peaks are detected on anodic $\mathrm{TiO}_{2}$ produced in $1 \mathrm{M} \mathrm{H}_{3} \mathrm{PO}_{4}$ on either as delivered foil or polished, thus indicating that the layers are completely amorphous, coherently with the low energy absorbed by the process and the absence of sparking. However, anatase peaks (at $25.4^{\circ}$ ) are detected by XRD on the layers grown in sulfuric acid electrolyte (Fig. 2c) at high voltage (90 V) for both untreated Ti foil ${ }^{35,39}$ and polished substrate. For the latter, the higher quantity of energy required during anodizing (as proved by the higher currents circulated in the cell, Fig. 1d) and the orientation of substrate grains can enhance amorphous-to-crystalline (anatase) transition. ${ }^{18,42}$ To confirm the presence of a crystal phase by XRD, three corresponding peaks were considered. ${ }^{44}$ For both $90 \mathrm{~V}$ samples, $\mathrm{S} 3$ and S5, besides the main anatase peak at $25.4^{\circ}$ several other anatase peaks were detected at $48.2^{\circ}, 54.2^{\circ}$ and $55.2^{\circ}$ but with accordingly lower intensities. In fact, the combination of high voltage, high current and surface pre-treatment of the sample leads to a higher amount of anatase crystals in S5 sample (polished Ti substrate, anodized at 90 $\mathrm{V})$ as it shows a more pronounced anatase peak at $25.4^{\circ}$ in the XRD pattern (see inset in Fig. 2c). No anatase crystal peaks were detected on the as-grown compact oxide obtained at $20 \mathrm{~V}$ in both electrolytes (data not shown).

To ensure a good evaluation of the thickness of compact oxide layers, oxide thicknesses were computed from reflectance spectra (see 
a) SEM images

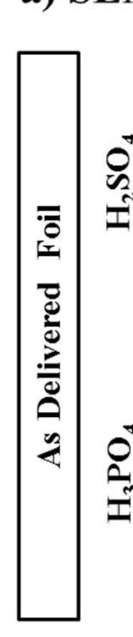

$50 \mathrm{~V}$
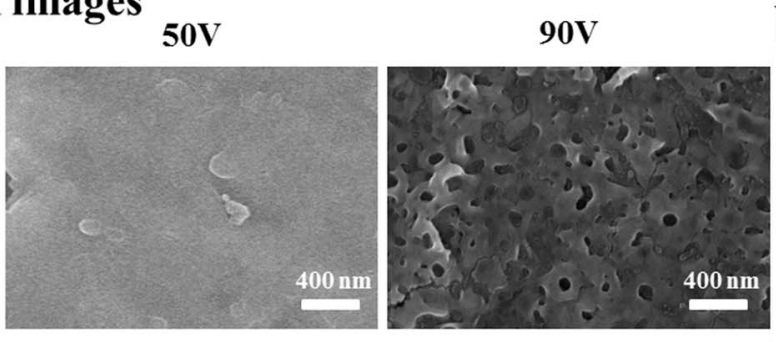

b) ${ }_{15}$
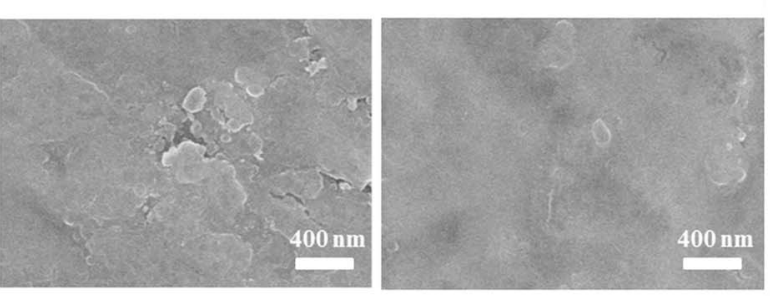

c)

d)

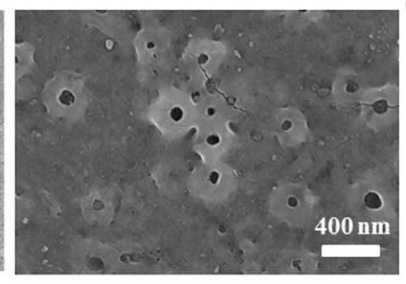

d)

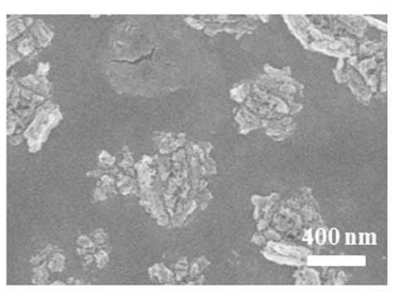

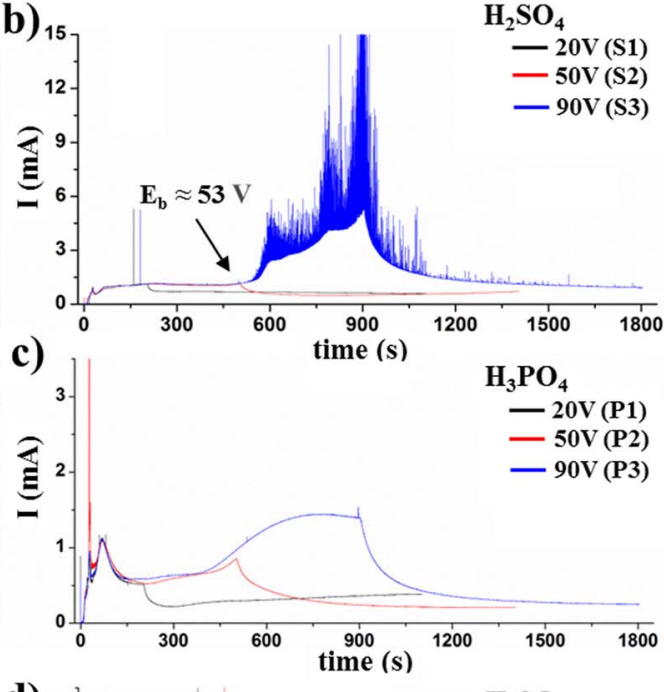
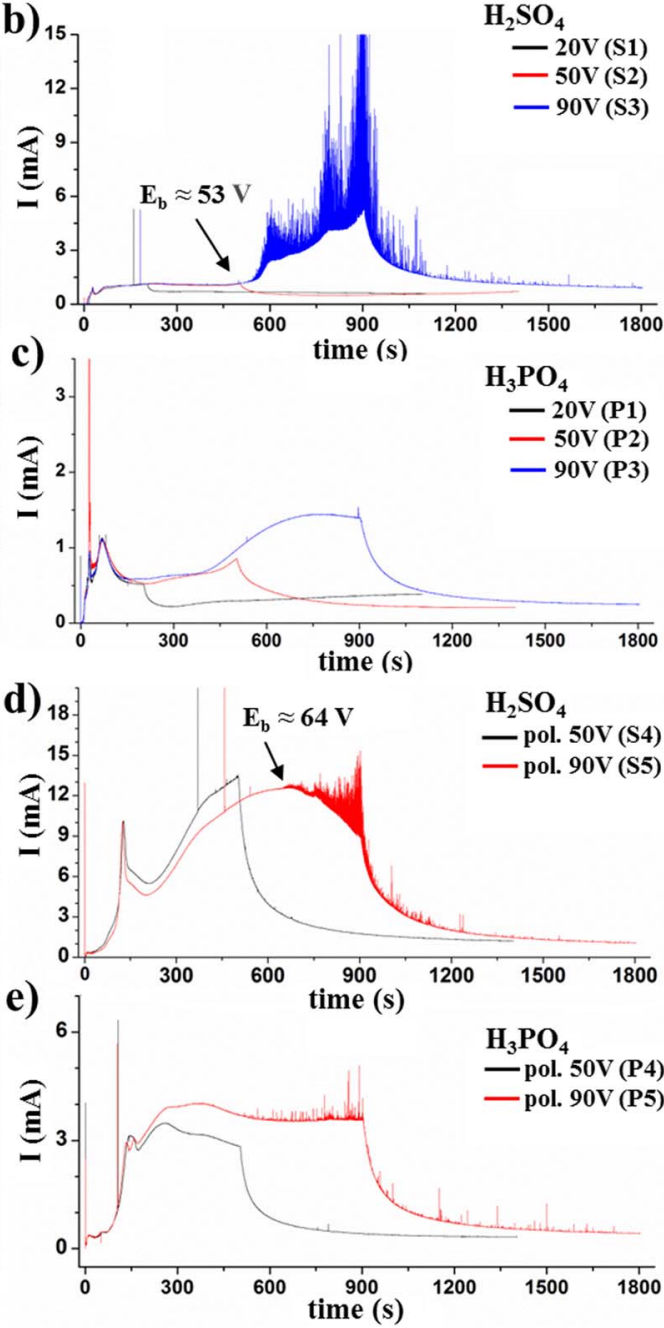

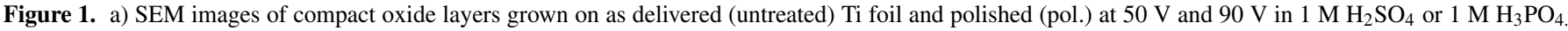
Current profiles for compact layers grown on untreated foil in: b) $\mathrm{H}_{2} \mathrm{SO}_{4}$ at $20 \mathrm{~V}(\mathrm{~S} 1), 50 \mathrm{~V}$ (S2) and $90 \mathrm{~V}$ (S3), c) $\mathrm{H}_{3} \mathrm{PO}_{4}$ at $20 \mathrm{~V}$ (P1), $50 \mathrm{~V}$ (P2) and $90 \mathrm{~V}$ (P3). Current profiles for compact layers grown on polished foil in: d) $\mathrm{H}_{2} \mathrm{SO}_{4}$ at $50 \mathrm{~V}$ (S4) and $90 \mathrm{~V}$ (S5), e) $\mathrm{H}_{3} \mathrm{PO}_{4}$ at $50 \mathrm{~V}$ (P4) and $90 \mathrm{~V}$ (P5).

Fig. 2a). ${ }^{39}$ Layers present a quasi-linear trend of thickness as a function of voltage (on as delivered $\mathrm{Ti}$ ) that is coherent with trends presented in literature, although anodizing ratios appear different $(\approx 2.6 \mathrm{~nm} / \mathrm{V}$ in sulfuric acid and $\approx 2.4 \mathrm{~nm} / \mathrm{V}$ in phosphoric acid). This may be ascribed to the difference in anodizing conditions, as most literature data refer to galvanostatic anodizing. The resulting oxide thickness is always lower if the anodic process is performed on pre-treated (pol.) substrates. Still, it is interesting to note that a more precise thickness estimation is possible on polished samples due to a better homogeneity of the oxide on the whole substrate surface. Consequently, reflectance peaks and valleys are deeper and the related maxima and minima are easier to distinguish, thus giving an optimal repeatability of the oxide thickness estimation on different peaks.

Further, we corroborated the thickness data from reflectance spectra with that from SEM cross-section images. Fig. 3 presents the cross-section images for selected samples $(20,50$ and $90 \mathrm{~V}$ on Ti foil in both electrolytes - S1, S2, S3 and P1, P2, P3) and there is a good correlation between the two methods. However a small difference can be observed due to two reasons: first, the layer thickness is not uniform and secondly, the porosity due to sparking. For the layer thickness's uniformity, for example for $\mathrm{S} 1$, from cross-section we observe a layer thickness of $78 \mathrm{~nm} \pm 10 \mathrm{~nm}$, while the thickness estimated from reflectance spectra is $85 \mathrm{~nm}$. For thicker layers, obtained at higher applied voltages ( $90 \mathrm{~V}, \mathrm{~S} 3$ and P3), this difference becomes more pro- nounced as values of $\approx 242 \mathrm{~nm} \pm 44 \mathrm{~nm}$ and $\approx 227 \mathrm{~nm} \pm 28 \mathrm{~nm}$ are observed from SEM cross-sections images, respectively. Secondly, especially when sparking occurs (i.e. $90 \mathrm{~V}$ in sulfuric acid - see S3), the difference between the two methods of measuring the thickness is also due to the porosity formed as a result of sparking. Finally, for all voltages the presence of bubbles inside the layer is observed, ascribed by Habazaki et al. ${ }^{18}$ to gas bubbles $\left(\mathrm{O}_{2}\right)$ occluded in the oxide. Further research by Mazzarolo et al.$^{40}$ has shown that in the case of $\mathrm{Ti}$, the amorphous to crystalline transition triggers an additional generation of oxygen bubbles in the oxide. More specifically, for the $90 \mathrm{~V}$ oxide grown in sulfuric acid (S3) the anodic layer is composed of two different layers: a $\approx 120 \mathrm{~nm}$ thick upper-layer in contact with the electrolyte, having a "smooth" appearance and porosity typical of sparking, and an inner layer (in contact with the metal substrate) where occlusion of gas bubbles is observed (inside the inner layer and also at the interface with the metal). Overall, the trend for layer thicknesses observed from SEM is consistent with that estimated from reflectance data, namely compact anodic layers grown in sulfuric acid have a slightly higher thickness (increased by $\approx 15-20 \mathrm{~nm}$ ) compared to phosphoric acid. It is worth pointing out that for polished substrates mechanically cracking the sample is not viable and accurate SEM cross-section data cannot be measured just by scratching the samples, as the oxide layer breaks off due to the occlusion of gas bubbles. 

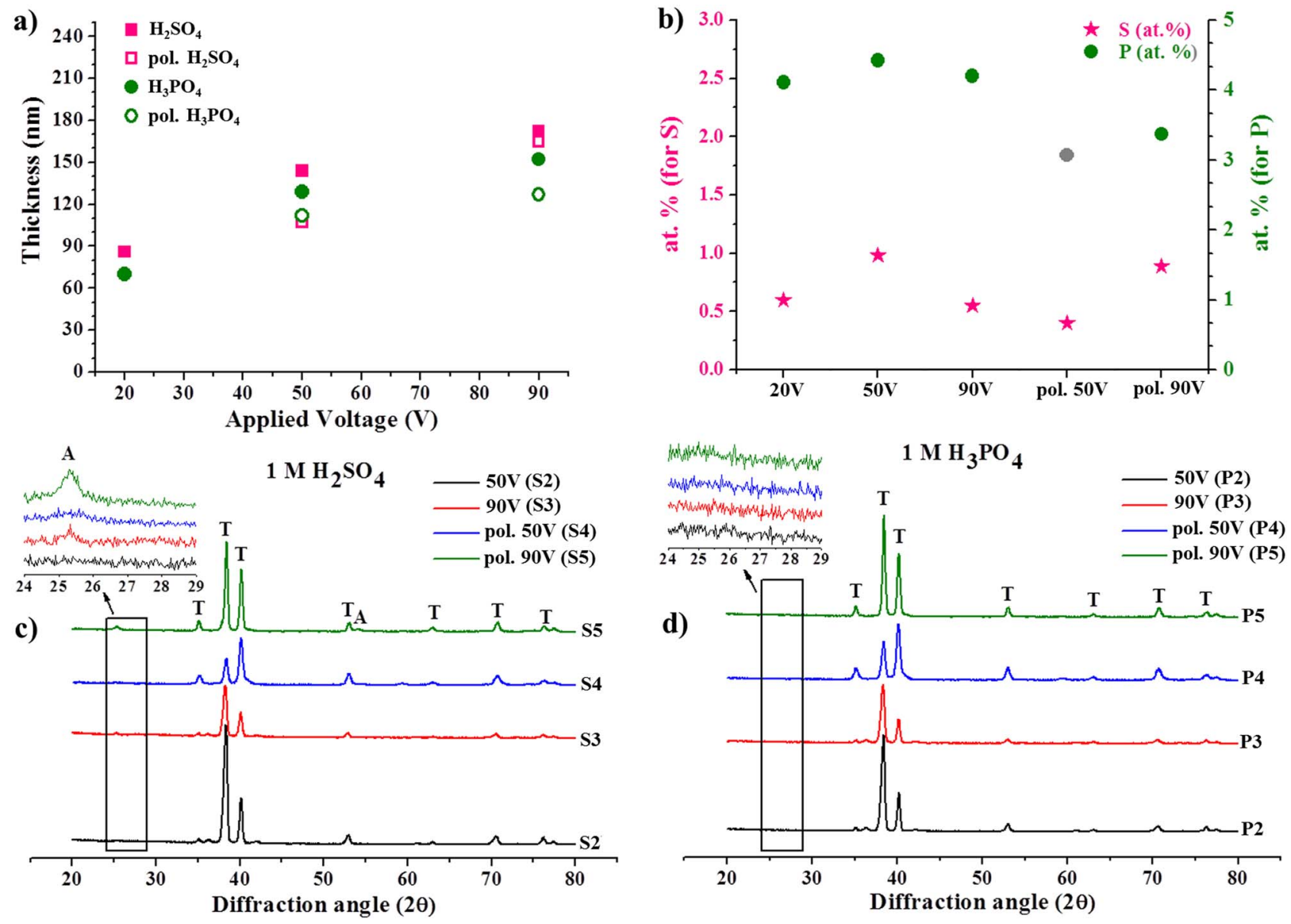

Figure 2. a) Thickness of the anodic compact oxides as a function of the applied voltage computed from reflectance spectra; b) Ion incorporation from the electrolyte computed from XPS measurements: $\mathrm{S}$ (left side) and $\mathrm{P}$ (right side) at.\%; XRD plots of compact oxides (inset: higher magnification) grown in c) $\mathrm{H}_{2} \mathrm{SO}_{4}$ or d) $\mathrm{H}_{3} \mathrm{PO}_{4}(\mathrm{~A}$ - anatase and $\mathrm{T}$ - titanium, from the substrate).

Besides the negligible difference in the anodizing ratio for oxides grown in sulfuric or phosphoric electrolytes, incorporation of ions was found to strongly characterize the grown layers (see Fig. 2b). As a matter of fact, phosphate ions $(\mathrm{P})$ content within the layers was evaluated to $\approx 4$ at. $\%$, with a slight decrease to $\approx 3.25$ at. $\%$ for polished (pol.) samples (P4, P5), whereas incorporation of sulfate (S) ions is, in all cases, between $0.5-1$ at.\%. The amount of incorporated ions is almost invariant with the applied voltage, as reported in literature for both $\mathrm{TiO}_{2}{ }^{24}$ and anodic oxides grown on other valve metals. ${ }^{45}$

Oxides photoactivity. - In order to evaluate photoelectrochemical properties, photocurrent spectra (Figs. $4 \mathrm{a}$ and $4 \mathrm{c}$ ) were acquired in $0.1 \mathrm{M} \mathrm{Na}_{2} \mathrm{SO}_{4}$ electrolyte. For evaluating the photocatalytic properties, efficiency trends for photodegradation of AO7 (Figs. 4b and 4d) were measured. IPCE (Incident Photon-to-Current Efficiency) plots and efficiency in $\mathrm{AO} 7$ photodegradation of the compact oxide layers clearly show that the behavior of anodic $\mathrm{TiO}_{2}$ is strongly influenced by the electrolyte used and by the voltage applied during anodizing (Fig. 4). In fact, oxide layers grown at $20 \mathrm{~V}$ or $50 \mathrm{~V}$, independently of the electrolyte (samples S1, S2, P1 and P2), have similar efficiencies in both applications, i.e. having a maximum IPCE between $0.3-0.9 \%$ (although in literature IPCE of $\approx 4 \%$ for as-grown $20 \mathrm{~V}$ compact layers in ammonium sulfate electrolyte are reported ${ }^{30}$ ) and photodegradation rates between $0.012-0.017 \mathrm{~h}^{-1}$. Different behaviors are noticed for the samples produced at $90 \mathrm{~V}$ (samples S3 and P3): the oxide grown in $\mathrm{H}_{2} \mathrm{SO}_{4}$ is more active (S3 - IPCE: $6.6 \%$; DD: $0.086 \mathrm{~h}^{-1}$ ) than the one in $\mathrm{H}_{3} \mathrm{PO}_{4}(\mathrm{P} 3)$, and the efficiency of $\mathrm{P} 3$ is coherent with low voltage compact oxides. The higher photoactivity for $\mathrm{S} 3$ can be ascribed to the presence of anatase crystals, which are not present in P3. A similar conclusion can be drawn for the oxides grown on polished substrates at high voltages $(90 \mathrm{~V})$, which are highly active if anodizing is carried out in sulfuric acid (mainly due to the higher content of anatase crystals), whereas the oxide layer obtained in phosphoric acid has low activity. Additionally, the highest efficiencies for as-grown compact oxides in both IPCE and dye decomposition are obtained by S5 (anodized at $90 \mathrm{~V}$ in $\mathrm{H}_{2} \mathrm{SO}_{4}$, on polished substrate) which also showed the most pronounced main anatase peak. It follows that for the as-grown investigated compact layers, the key factor ruling their photoactivity is the crystallinity degree, particularly the presence of anatase crystals. ${ }^{46}$ In this scenario, the electrolyte used during oxide growth strongly influences the performance of the layer, due to the formation of partially crystalline or amorphous oxide during the anodic process (at high voltage). In the case of phosphoric acid, its efficiency can be correlated with the low content of anatase phase - owing to a delayed oxide crystallization in presence of such a large quantity of phosphate ions that constitute an obstacle to short and long range ordering. ${ }^{24,47}$

To further investigate the influence of crystallinity on IPCE and dye decomposition, compact oxides obtained in both sulfuric (S1$\mathrm{S} 5$ ) and phosphoric (P1-P5) acids were subjected to a post-annealing treatment (at $450^{\circ} \mathrm{C}$ for $1 \mathrm{~h}$ ) to ensure conversion to anatase. The thicknesses of the annealed compact oxide layers were computed from reflectance spectra and an increase in the average thickness is 

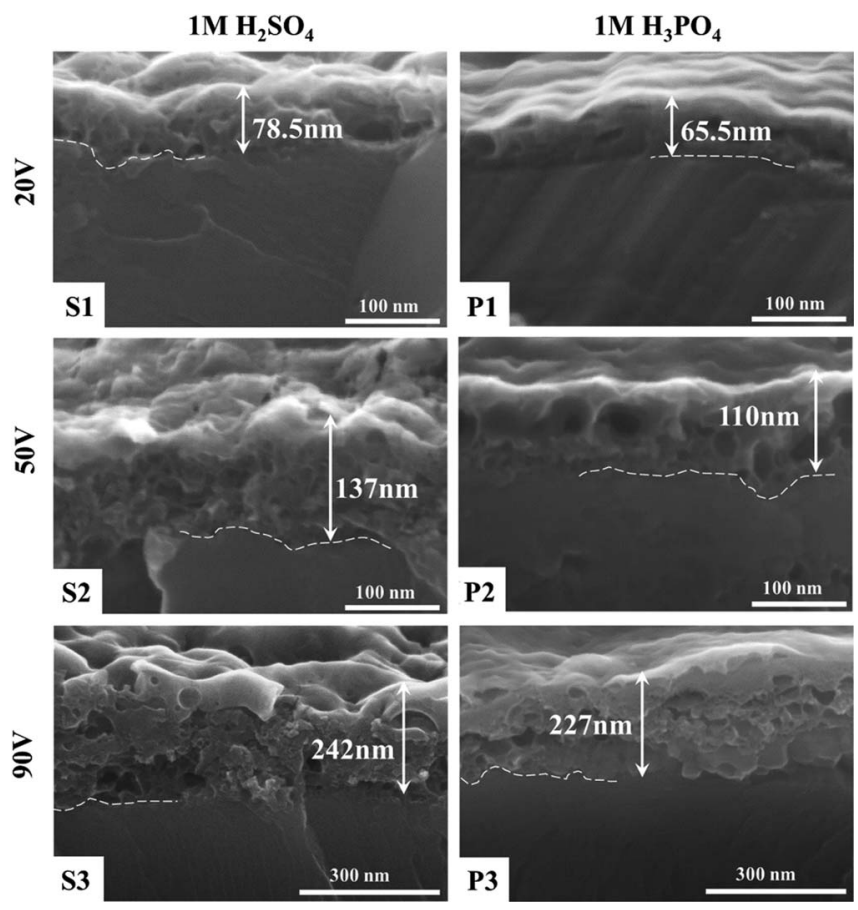

Figure 3. SEM cross-section images of compact oxides grown in $\mathrm{H}_{2} \mathrm{SO}_{4}$ at $20 \mathrm{~V}(\mathrm{~S} 1), 50 \mathrm{~V}(\mathrm{~S} 2), 90 \mathrm{~V}(\mathrm{~S} 3)$ and in $\mathrm{H}_{3} \mathrm{PO}_{4}$ at $20 \mathrm{~V}(\mathrm{P} 1), 50 \mathrm{~V}(\mathrm{P} 2), 90 \mathrm{~V}$ (P3). observed (Figs. 5a and 5b). This is due to formation of a thermal rutile oxide layer at the compact oxide / metal interface, as indicated in Figs. 5c and 5d which compares the SEM cross-sections of the $90 \mathrm{~V}$ as-grown compact layer (S3) with the annealed one (S3-Ann). After annealing, the presence of an intermediate layer between the metallic substrate and the anodic oxide (inner layer containing also gas bubbles) is observed. For the as-grown layer, the oxide / metal interface is easy to follow, due to the metal substrate and to the presence of bubbles inside the layer. ${ }^{18}$ It is well known that during annealing (thermal oxidation) of just a plain Ti substrate, thin rutile thermal oxide layers are obtained. ${ }^{48-50}$ The rutile thermal layer grows from the titanium substrate ${ }^{50}$ and augments the existing thickness of the compact oxide layer, and further anatase to rutile conversion inside the oxide layer takes place. This intermediate thermal layer observed by SEM $(\approx 80 \mathrm{~nm})$ corroborates the increase in thickness observed by spectrophotometry in Fig. 5a. No change was observed in the top morphology of the compact layers as a result of annealing, as indicated for S3 in the high-magnification top view images in Figs. $5 \mathrm{c}$ and $5 \mathrm{~d}$. In addition, the thermal oxide layers obtained under similar conditions on nanostructured $\mathrm{TiO}_{2}$ layers ${ }^{50}$ are much thicker than those obtained on plain $\mathrm{Ti}^{50-52}$

Furthermore, the content of incorporated ions was examined by XPS and similar values as before annealing were obtained, although a slight decrease is observed $(\mathrm{S} \approx 0.5$ at. $\%$ while $\mathrm{P} \approx 3$ at. $\%$ - see Fig. 6 a). An exception is the oxide grown on polished substrate at $90 \mathrm{~V}$, that shows higher incorporated ions contents after annealing, with $\mathrm{S}$ content of $\approx 1.0$ at. $\%$ and $\mathrm{P}$ content of $\approx 5.7$ at. $\%$. Next, XRD spectra were measured in the $20-80$ angular range and Fig. $6 \mathrm{~b}$ and $6 \mathrm{c}$ list only the $22-30$ angular range indicating both anatase and rutile main peaks
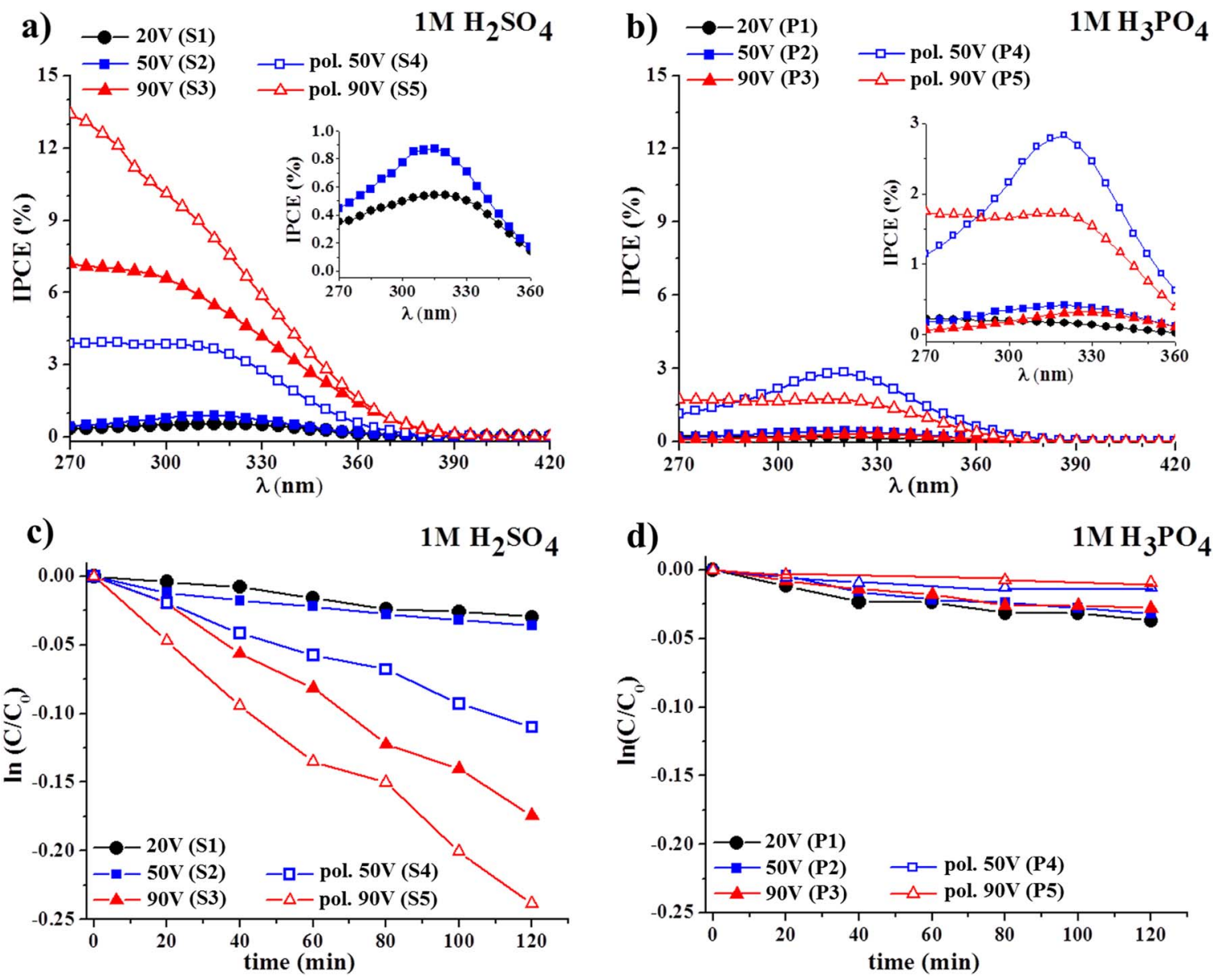

Figure 4. IPCE plots of anodic compact layers grown in a) $\mathrm{H}_{2} \mathrm{SO}_{4}$ or b) $\mathrm{H}_{3} \mathrm{PO}_{4}$. Dye degradation kinetics (AO7) for as-grown anodic compact layers obtained in c) $\mathrm{H}_{2} \mathrm{SO}_{4}$ or d) $\mathrm{H}_{3} \mathrm{PO}_{4}$. 


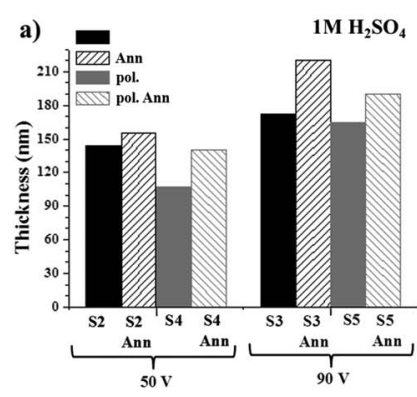

c) $\mathrm{S3}\left(90 \mathrm{~V} \mathrm{H}_{2} \mathrm{SO}_{4}\right.$ as-grown)
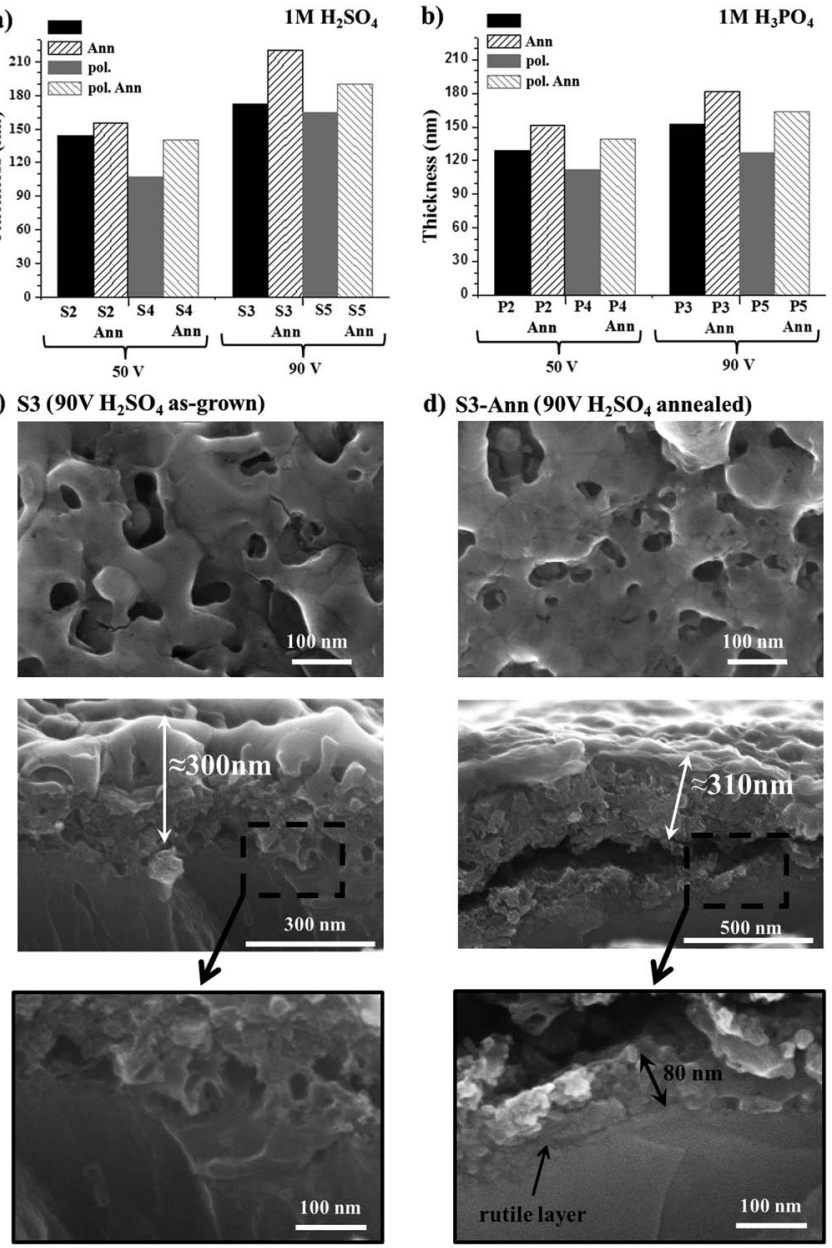

Figure 5. Influence of annealing on thickness, computed from reflectance spectra, for selected compact oxides $(50 \mathrm{~V}$ and $90 \mathrm{~V}$ on untreated or polished foil): a) $\mathrm{H}_{2} \mathrm{SO}_{4}$ or b) $\mathrm{H}_{3} \mathrm{PO}_{4}$. SEM cross-section images of annealing effect on compact oxides grown at $90 \mathrm{~V}$ in sulfuric acid: c) as-grown layer (S3), and d) annealed layer (S3-Ann).

(independently of the electrolyte used during oxide growth) and their intensities are higher for oxides produced at high voltage $(90 \mathrm{~V})$. For both anatase and rutile, also the corresponding lower intensities peaks were recorded i.e at $48.2^{\circ}, 54.2^{\circ}$ and $55.2^{\circ}$ for anatase, and at $36.1^{\circ}$, $41.0^{\circ}$ and $54.3^{\circ}$ for rutile.

Concerning the annealed oxides grown in sulfuric acid at 20 or 50 $\mathrm{V}$ (Figs. 7a and 7c), generally performances (IPCE and dye decomposition) are similar to those of the $90 \mathrm{~V}$ oxide (S3), both before and after annealing, further confirming the key role of crystal structure on $\mathrm{TiO}_{2}$ photoactivity. Furthermore, efficiency values for annealed 20 $\mathrm{V}$ compact oxides are in accordance with literature data for compact layers with at least similar annealing temperature $\left(450^{\circ} \mathrm{C}\right),{ }^{30,31,34}$ i.e. IPCE values of $\approx 8 \%{ }^{30}$ and $\mathrm{AO} 7$ dye decomposition photodegradation rates of $\approx 0.08 \mathrm{~h}^{-1}$. $^{34}$

On the other hand, compact oxides grown on polished substrates in sulfuric acid show the highest performances in both applications, with the maximum IPCE value of the current work of $15.3 \%$ and a photodegradation rate of $\approx 0.21 \mathrm{~h}^{-1}$. However, the annealed $90 \mathrm{~V}$ compact oxide grown on polished substrate shows the highest IPCE, while the highest photodegradation rate is for that at $50 \mathrm{~V}$. This unexpected result could be related to the different anatase to rutile ratios of the two oxides: in fact, on the $50 \mathrm{~V}$ oxide the rutile content appears slightly higher, which in this case seems to favor dye photodegradation. Furthermore, analogously to oxides grown in $\mathrm{H}_{2} \mathrm{SO}_{4}$ on as delivered foil, annealing improves the performance of oxides grown

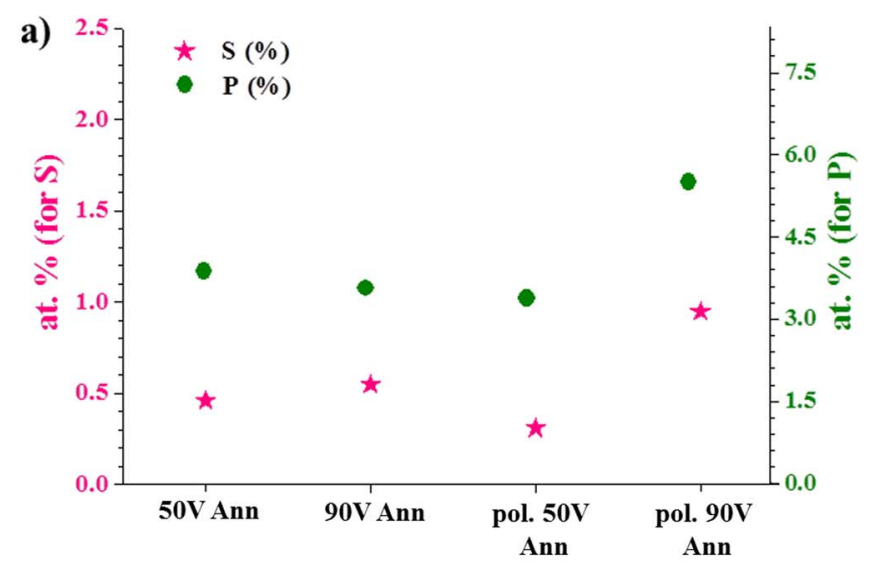

b) $1 \mathrm{M} \mathrm{H}_{2} \mathrm{SO}_{4}$

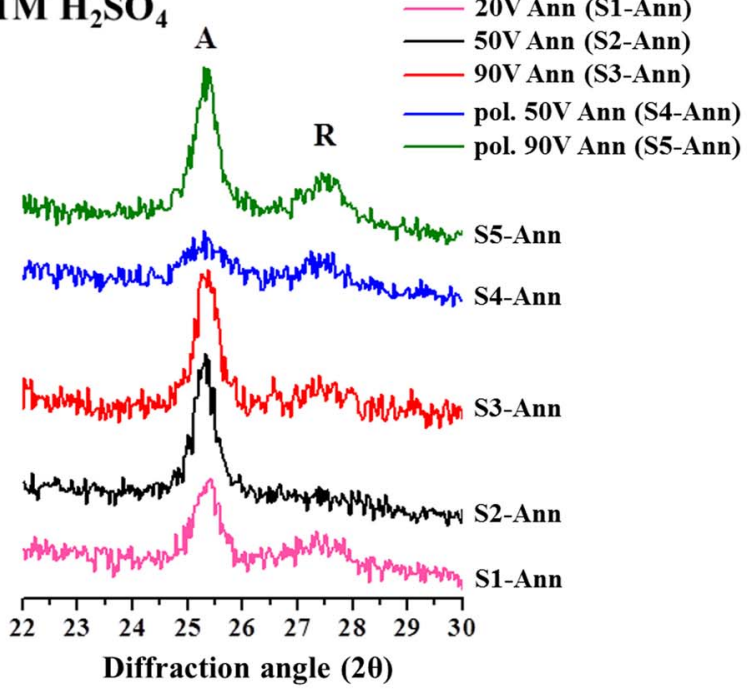

c) $1 \mathrm{M} \mathrm{H}_{3} \mathrm{PO}_{4}$

- 50V Ann (P2-Ann)

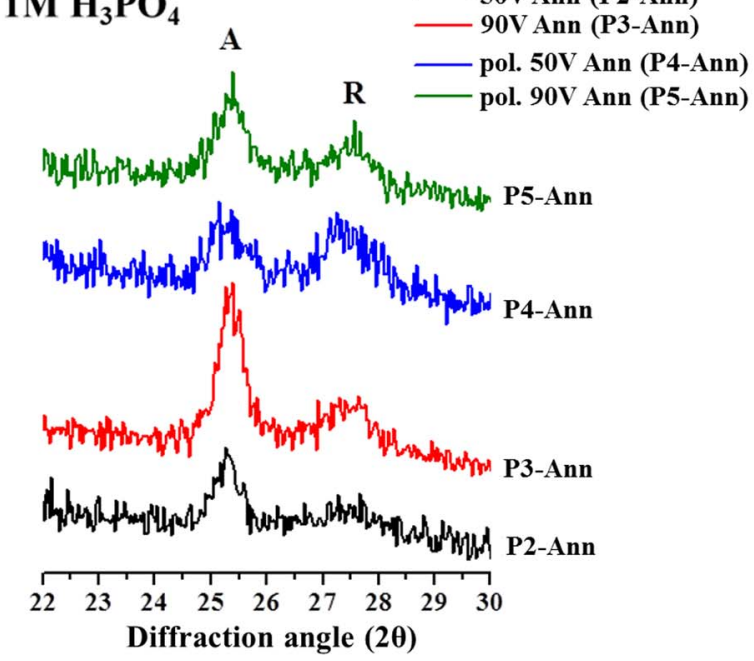

Figure 6. a) Ion incorporation from the electrolyte in the annealed layers computed from XPS measurements: S (left side) and P (right side) at.\%; XRD plots of the 22-30 angular range for annealed compact oxides obtained in b) $\mathrm{H}_{2} \mathrm{SO}_{4}$ or c) $\mathrm{H}_{3} \mathrm{PO}_{4}(\mathrm{~A}$ - anatase and $\mathrm{R}$ - rutile).

on polished substrates in both IPCE (as shown in Fig. 7a, indicating also as reference line the P5 sample - as-grown pol. $90 \mathrm{~V}$ compact oxide layer) and photodegradation rates (Fig. 7c). Photodegradation rates for selected as-grown and annealed compact oxides are listed in Table II. 

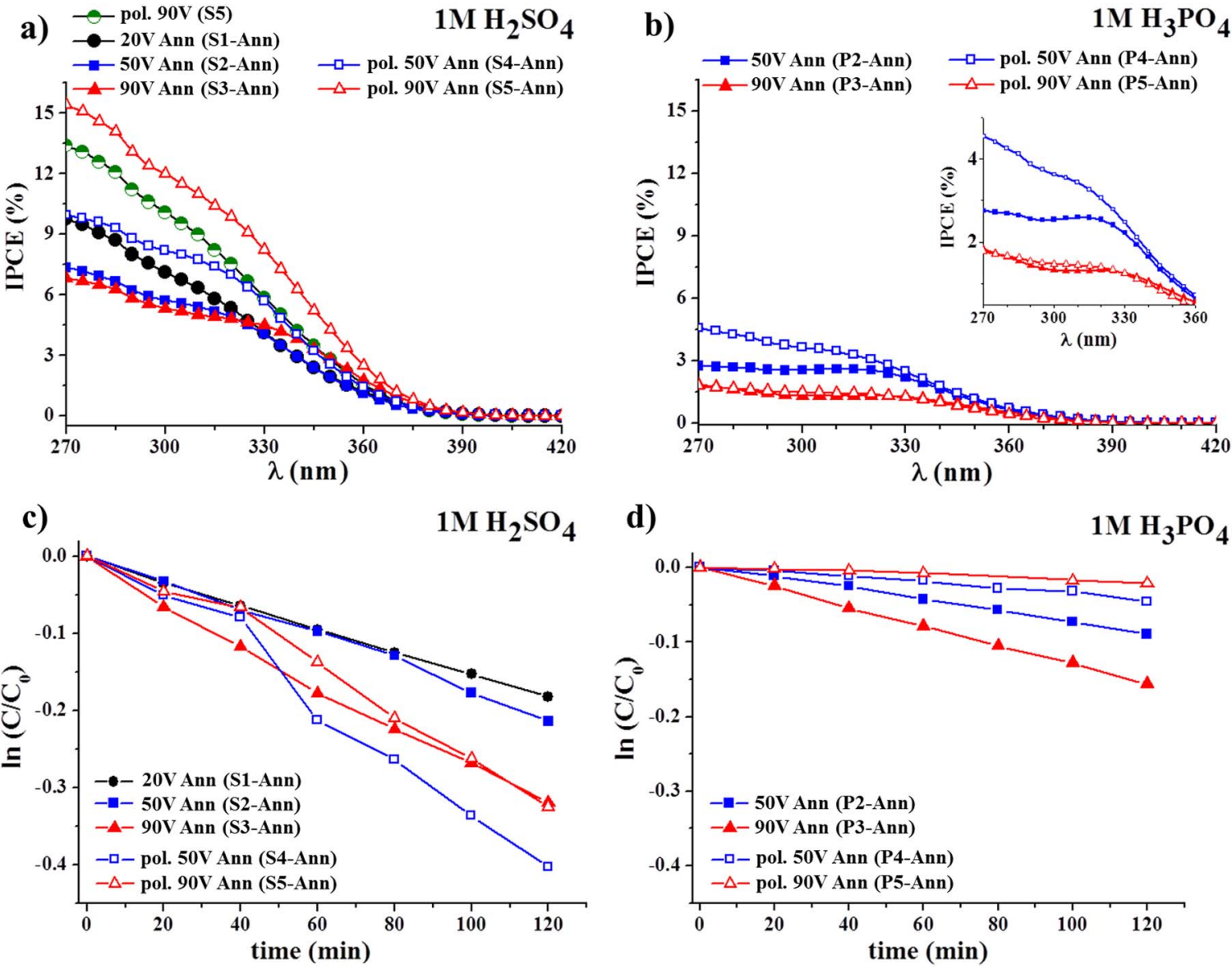

Figure 7. IPCE plots of annealed compact layers grown in a) $\mathrm{H}_{2} \mathrm{SO}_{4}$ or b) $\mathrm{H}_{3} \mathrm{PO}_{4}$. Dye degradation kinetics (AO7) for annealed anodic compact layers obtained in c) $\mathrm{H}_{2} \mathrm{SO}_{4}$ or d) $\mathrm{H}_{3} \mathrm{PO}_{4}$.

Oxides obtained in $\mathrm{H}_{3} \mathrm{PO}_{4}$ show a different behavior with respect to what we previously described for $\mathrm{H}_{2} \mathrm{SO}_{4}$. In fact, despite the presence of anatase crystals after annealing, performances are visibly lower with a max. IPCE of $\approx 5 \%$ and photodegradation rates below $0.08 \mathrm{~h}^{-1}$ (Fig. 7, Table II). Due to the similar morphology and crystal structure, the difference in efficiency can be related to the incorporated ions, showing a direct negative effect on $\mathrm{PO}_{4}{ }^{3-}$ inclusions on $\mathrm{TiO}_{2}$ photocatalytic properties. Focusing on the photocurrent spectra, it seems that after annealing, the most important ruling factors in determining oxides activity are annealing, followed by applied voltage. Namely, the $50 \mathrm{~V}$ compact oxide is more active than the $90 \mathrm{~V}$, independent of the Ti substrate (as delivered or polished foil). On the other hand, analysis of the photodegradation kinetics shows that the pre-treatment has a higher influence on the material performance

Table II. Photodegradation rates for selected as-grown and annealed compact oxide layers.

$K$ - photodegradation rate

\begin{tabular}{lll}
\cline { 2 - 3 } Sample & $1 \mathrm{M} \mathrm{H}_{2} \mathrm{SO}_{4}$ & $1 \mathrm{M} \mathrm{H}_{3} \mathrm{PO}_{4}$ \\
\hline $50 \mathrm{~V}$ (S2/P2) & $0.0168 \mathrm{~h}^{-1}$ & $0.0162 \mathrm{~h}^{-1}$ \\
$90 \mathrm{~V}$ (S3/P3) & $0.0858 \mathrm{~h}^{-1}$ & $0.0140 \mathrm{~h}^{-1}$ \\
pol. 50 V (S4/P4) & $0.0539 \mathrm{~h}^{-1}$ & $0.0063 \mathrm{~h}^{-1}$ \\
pol. 90 V (S5/P5) & $0.1158 \mathrm{~h}^{-1}$ & $0.0044 \mathrm{~h}^{-1}$ \\
$50 \mathrm{~V}$ annealed (S2-Ann/P2-Ann) & $0.1062 \mathrm{~h}^{-1}$ & $0.0454 \mathrm{~h}^{-1}$ \\
$90 \mathrm{~V}$ annealed (S3-Ann/P3-Ann) & $0.1572 \mathrm{~h}^{-1}$ & $0.0780 \mathrm{~h}^{-1}$ \\
pol. 50 V annealed (S4-Ann/P4-Ann) & $0.2101 \mathrm{~h}^{-1}$ & $0.0226 \mathrm{~h}^{-1}$ \\
pol. 90 V annealed (S5-Ann/P5-Ann) & $0.1662 \mathrm{~h}^{-1}$ & $0.0111 \mathrm{~h}^{-1}$
\end{tabular}

(Fig. 7d); yet, these effects are observed on extremely low activities, therefore such differences are less relevant.

Considerations. - From the presented results it is possible to draw some considerations on the effects of anodizing parameters on the photoefficiency of anodic oxides, starting with the important role of the applied voltage for as-grown oxides: the higher the voltage, the higher the oxide crystallinity and therefore its activity. However, this rule is lost when as-grown oxides are annealed, since the extra energy required for the oxides to crystallize is now provided thermally instead of electrochemically. From this point of view, it is also important to observe how the energy absorbed in the process influences the final efficiencies of oxides prior to annealing. As a matter of fact, when the substrate is polished, a higher current is required to reach a given voltage compared to the untreated substrate, and this leads to a larger crystallization extent and to a higher photoactivity in spite of a slightly lower oxide thickness.

Considering now the role of annealing, in photocurrent measurements it is crucial to consider the effect of the rutile thermal layer, responsible for the increase in layer thickness (indicated in the SEM cross-section of the annealed oxide grown at $90 \mathrm{~V}$ in sulfuric acid, reported in Fig. 5d). Such layers can act as a limiting factor in terms of charge mobility, and thus compact oxide layers grow on as delivered foil at 20, 50 or $90 \mathrm{~V}$ have, after annealing (S1-Ann, S2-Ann, S3Ann), similar IPCE trends. On the other hand, photodegradation does not seem to be affected by this intermediate layer, reasonably because such a layer does not come into contact with the outer environment, where photodegradation reactions take place: therefore. Hence, for photodegradation only the beneficial effect of increased crystallinity appears and leads to a higher efficiency after annealing. 
Finally, it is evident that $\mathrm{P}$ inclusions cause a reduction of the photocurrent and dye decomposition of $\mathrm{TiO}_{2}$. Moreover, incorporation of ions could have a direct effect on photo-induced phenomena in anodic $\mathrm{TiO}_{2}$ especially considering the peculiar trends observed in the two different processes. i.e. samples anodized in phosphates at 50 $\mathrm{V}$ and further annealed showed relatively high IPCE, $4.4 \%$, while all annealed layers show very low photodegradation kinetics with rates of $0.01-0.08 \mathrm{~h}^{-1}$. Therefore, it is possible to state that the inclusion of $\mathrm{PO}_{4}{ }^{3-}$ ions has a negative effect, and avoiding phosphates containing solutions as electrolytes for compact anodic $\mathrm{TiO}_{2}$ represents a good strategy in order to produce high performance anodic compact oxide films. Furthermore, for sulfates based electrolytes, higher efficiencies can be obtained with an optimal combination of high-voltage anodizing (e.g. $90 \mathrm{~V}$ ), substrate pre-treatment and annealing treatment.

\section{Conclusions}

The present results highlight the importance of anodic oxidation conditions alongside surface pre-treatment and annealing to enhance the photo(electro)chemical properties of $\mathrm{TiO}_{2}$ compact oxide layers, in particular for photocurrent generation and photocatalytic dye decomposition. Results clearly indicate the importance of electrolyte and applied voltage in determining the occurrence of anodic spark deposition conditions and oxide crystallization, which improves the photocatalytic properties. Additionally, substrate's polishing further increases crystallinity when performing anodic oxidation in sulfuric acid at high voltage. The presence of crystallinity in as-grown oxides is strongly related to the electrolyte used, as in phosphoric acid no crystalline oxide phase was detected, as a consequence of the breakdown (and therefore crystallization) delay caused by the large presence of phosphate ions. This contrasts with the lower atomic percentage of sulfur identified in the oxide, which guarantees an easier ordering and consequent crystallization.

As expected, annealing increased the layers crystallinity, independent of the electrolyte used in anodizing, and leads to the formation of both anatase and rutile phases. However, annealing also causes the formation of a rutile layer at the compact oxide / metal interface which has an influence on the photocurrent response, as it decreases charge carriers transport efficiency by forming a further interface before the collecting substrate. Conversely, thermal annealing still ensures an improvement of the photocatalytic performance in terms of dye degradation, where the oxide surface morphology and overall crystallinity are the ruling parameters in determining its efficiency. These results elucidate a number of critical parameters in designing compact anodic oxide layers for enhancing their photocatalytic properties.

\section{Acknowledgments}

Ulrike Marten-Jahns is acknowledged for XRD measurements. DFG and the Erlangen DFG cluster of excellence are acknowledged for financial support.

\section{References}

1. T. Shibata and Y. C. Zhu, The effect of film formation conditions on the structure and composition of anodic oxide films on titanium, Corros. Sci., 37, 253 (1995).

2. S. Van Gils, P. Mast, E. Stijns, and E. Terryn, Color properties of barrier anodic oxide films on aluminum and titanium studied with total reflectance and spectroscopic ellipsometry, Surf. Coat. Technol., 185, 303 (2004)

3. M. V. Diamanti and M. P. Pedeferri, Effect of anodic oxidation parameters on the titanium oxides formation, Corros. Sci., 49, 939 (2007).

4. M. V. Diamanti, B. Del Curto, and M. P. Pedeferri, Anodic oxidation of titanium: From technical aspects to biomedical applications, J. Appl. Biomater Biom., 9, 55 (2011).

5. J. F. Vanhumbeeck and J. Proost, Current understanding of ti anodization: Functional, morphological, chemical and mechanical aspects, Corros. Rev., 27, 117 (2009).

6. M. V. Diamanti, M. Ormellese, and M. P. Pedeferri, Application-wise nanostructuring of anodic films on titanium: a review, J. Exp. Nanosci., 10(17), 1285 (2015).

7. S. D. Brown and G. P. Wirtz, Formation of ceramic coatings by anodic spark deposition - a review, Proceedings - The Electrochemical Society, 86(11), 138 (1986).
8. J. P. Schreckenbach, G. Marx, F. Schlottig, M. Textor, and N. D. Spencer, Characterization of Anodic Spark-Converted Titanium Surfaces for Biomedical Applications, J. Mat. Sci.: Mat. Med., 10, 453 (1999).

9. K. Lee, A. Mazare, and P. Schmuki, One-Dimensional Titanium Dioxide Nanomaterials: Nanotubes, Chem. Rev., 114, 9385 (2014).

10. D. Kowalski, D. Kim, and P. Schmuki, $\mathrm{TiO}_{2}$ nanotubes, nanochannels and mesosponge: Self-organized formation and applications, Nano Today, 8, 235 (2013).

11. K. Nakata and A. Fujishima, $\mathrm{TiO}_{2}$ photocatalysis: Design and application, J. Photochem. Photobiol. C, 13, 169 (2012).

12. E. Matykina, M. Montuori, J. Gough, F. Monfort, A. Berkani, P. Skeldon, G. E. Thompson, and H. Habazaki, Spark anodizing of titanium for biomedical applications, Trans. Inst. Met. Finishing, 84, 125 (2006).

13. A. Fujishima and K. Honda, Electrochemical photolysis of water at a semiconductor electrode, Nature, 238, 37 (1972).

14. M. Grätzel, Photoelectrochemical cells, Nature, 414, 338 (2001)

15. R. Wang, N. Sakai, A. Fujishima, T. Watanabe, and K. Hashimoto, Studies of surface wettability conversion on $\mathrm{TiO}_{2}$ single-crystal surfaces, J. Phys. Chem. B, 103, 2188 (1999).

16. K. Nakata and A. Fujshima, $\mathrm{TiO}_{2}$ photocatalysis: Design and applications, J. Photochem. Photobio. C, 13, 169 (2012).

17. T. Noguchi, A. Fujishima, P. Sawunyama, and K. Hashimoto, Photocatalytic degradation of gaseous formaldehyde using $\mathrm{TiO}_{2}$ films, Environ. Sci. Technol., 32, 3831 (1998).

18. H. Habazaki, M. Uozumi, H. Konno, K. Shimizu, P. Skeldon, and G. E. Thompson, Crystallization of anodic titania on titanium and its alloys, Corros. Sci., 45, 2063 (2003).

19. H. J. Song, M. K. Kim, G. C. Jung, M. S. Vang, and Y. J. Park, The effects of spark anodizing treatment of pure titanium metals and titanium alloys on corrosion characteristics, Sur. Coat. Techol., 201, 8738 (2007).

20. Y. T. Sul, C. B. Johansson, S. Petronis, A. Krozer, Y. Jeong, A. Wennerberg, and T. Albrektsson, Characteristics of the surface oxides on turned and electrochemically oxidized pure titanium implants up to dielectric breakdown: the oxide thickness, micropore configurations, surface roughness, crystal structure and chemical composition, Biomaterials, 23, 491 (2002)

21. S. Komiya, K. Sakamoto, and H. Ohtsu, Structural changes of anodic layer on titanium in sulfate solutions as a function of anodization duration in constant current mode, Appl. Surf. Sci., 296, 163 (2014).

22. B. Yang, M. Uchida, H. M. Kim, X. Zhang, and T. Kokubo, Preparation of Bioactive Titanium Metal via Anodic Oxidation Treatment, Biomaterials, 25, 1003 (2004)

23. Y. K. Shin, W. S. Chae, Y. W. Song, and Y. M. Sung, Formation of titania photocatalyst films by microarc oxidation of Ti and Ti-6Al-7Nb alloys, Electrochem. Commun., 8, 465 (2006)

24. S. Uttiya, D. Contarino, S. Prandi, M. M. Carnasciali, G. Gemme, L. Mattera, R. Rolandi, M. Canepa, and O. Cavalleri, Anodic Oxidation of Titanium in Sulfuric Acid and Phosphoric Acid Electrolytes, J. Mat. Sc. Nano., 1(1), S106 (2014).

25. T. Ohtsuka and T. Otsuki, The influence of the growth rate on the semiconductive properties of titanium anodic oxide, Corros. Sci., 40(6), 951 (1998).

26. A. Aladjem, Review: Anodic oxidation of titanium and its alloy, J. Mater. Sci., 8, 688 (1973).

27. M. Kozlowski, W. H. Smyrl, Lj. Atanasoska, and R. Ananasoski, Local film thickness and photoresponse of thin anodic $\mathrm{TiO}_{2}$ films on polycrystalline titanium, Electrochim. Acta, 34, 1763 (1989).

28. C. S. McMillan, J. P. H. Sukamto, and W. H. Smyrl, Surface-controlled Photoelectrochemical Microscopy of Thin Metal Oxide Films, Faraday Discuss., 94, 63 (1992).

29. S. Piazza, L. Calà, C. Sunseri, and F. Di Quarto, Influence of the crystallization process on the photoelectrochemical behavior of anodic $\mathrm{TiO}_{2}$ films, Berich. Bunsen. Gesell., 101, 932 (1997).

30. R. Beranek, H. Tsuchiya, T. Sugishima, J. M. Macak, L. Taveira, S. Fujimoto, H. Kisch, and P. Schmuki, Enhancement and limits of the photoelectrochemical response from anodic $\mathrm{TiO}_{2}$ nanotubes, Appl. Phy. Lett., 87, 243114 (2005).

31. H. Tsuchiya, J. M. Macak, A. Ghicov, A. S. Rader, L. Taveira, and P. Schmuki, Characterization of electronic properties of $\mathrm{TiO}_{2}$ nanotube films, Corros. Sci., 49, 203 (2007).

32. O. Carp, C. L. Huisman, and A. Reller, Photoinduced reactivity of titanium dioxide, Prog. Solid State Ch., 32(1-2), 33 (2004).

33. M. F. Brunella, M. V. Diamanti, M. P. Pedeferri, F. Di Fonzo, C. S. Casari, and A. L. Bassi, Photocatalytic behavior of different titanium dioxide layers, Thin Solid Films, 515, 6309 (2007).

34. J. M. Macak, H. Tsuchiya, A. Ghicov, K. Yasuda, R. Hahn, S. Bauer, and P. Schmuki, $\mathrm{TiO}_{2}$ nanotubes: Self-organized electrochemical formation, properties and applications, Curr. Opin. Solid St. M., 11, 3 (2007).

35. I. Parmasivam, J. M. Macak, and P. Schmuki, Photocatalytic activity of $\mathrm{TiO}_{2}$ nanotube layers loaded with $\mathrm{Ag}$ and $\mathrm{Au}$ nanoparticles, Electrochem. Commun., 10, 71 (2008).

36. H. J. Oh, J. H. Lee, and C. S. Chi, Photocatalytic characteristics of titania thin film prepared by micro arc oxidation, Key Eng. Mat., 543, 141 (2013).

37. R. J. Ramirez, C. A. P. Arellano, J. C. Varia, and S. S. Martinez, Visible light-induced photoctalytic elimination of organic pollutants by $\mathrm{TiO}_{2}$ : A review, Curr. Org. Chem., 19, $540(2015)$

38. M. V. Diamanti, B. Del Curto, M. P. Pedeferri, and A. Cigada, A comparative study over the photocatalytic activity of nanostructured $\mathrm{TiO}_{2}$ layers for air purifiers, Technical Proceedings of the 2011 NSTI Nanotechnology Conference and Expo, NSTINanotech 2011, 1, 425 (2011)

39. M. V. Diamanti, B. Del Curto, and M. P. Pedeferri, Interference colors of thin oxide layers on titanium, Color Res. Appl., 33, 221 (2008). 
40. A. Mazzarolo, M. Curioni, A. Vicenzo, P. Skeldon, and G. E. Thompson, Anodic growth of titanium oxide: Electrochemical behavior and morphological evolution, Electrochim. Acta, 75, 288 (2012).

41. E. Matykina, R. Arrabal, P. Skeldon, G. E. Thompson, and H. Habazaki, Influence of grain orientation on oxygen generation in anodic titania, Thin Solid Filmsm, 516, 2296 (2008).

42. A. Afshar and M. R. Vaezi, Evaluation of electrical breakdown of anodic films on titanium in phosphate-base solutions, Surf. Coat. Techol., 186, 398 (2004).

43. A. Nakahira, K. Konishi, K. Yokota, T. Honma, H. Aritani, and K. Tanaka, Synthesis and characterization of $\mathrm{TiO}_{2}$ doped with $\mathrm{P}$ ions by anodic oxidation of titanium in acid solution, J. Ceram. Soc. Jap., 114(1), 46 (2006).

44. A. R. West, Ed., Solid State Chemistry and its Applications, 2nd edition, Chapter 5. Crystallography and Diffraction Techniques, Wiley, UK (2014).

45. M. Sowa, K. Greń, A. I. Kukharenko, D. M. Korotin, J. Michalska L. Szyk-Warszyńska, and M. Mosiałek, , J. Żak, E. Pamuła, E. Z. Kurmaev, S. O. Cholakh, and W. Simka, Influence of electropolishing and anodic oxidation on morphology, chemical composition and corrosion resistance of niobium, Mater Sci. Eng. C, 42, 529 (2014).
46. T. Luttrell, S. Halpegamage, E. Sutter, and M. Batzill, Photocatalytic activity of anatase and rutile $\mathrm{TiO}_{2}$ epitaxial thin film grown by pulsed laser deposition, Thin Solid Films, 564, 146 (2014).

47. K. Konishi, T. Kubo, and A. Nakahira, Characterization of Some Properties of $\mathrm{TiO}_{2}$ on Ti surface by Anodization in Acid Solution, 14th International Conference on the Properties of Water and Steam in Kyoto, 391, (2013).

48. J. W. Hickman and E. A. Gulbransen, Oxide films formed on titanium, zirconium and their alloys with nickel, copper and cobalt, Anal. Chem., 20(2), 158 (1948).

49. C.-C. Ting and S.-Y. Chen, Structural evolution and optical properties of $\mathrm{TiO}_{2}$ thin films prepared by thermal oxidation of sputtered Ti films, J. Appl. Phys., 88, 4628 (2000).

50. S. P. Albu, H. Tsuchiya, S. Fujimoto, and P. Schmuki, $\mathrm{TiO}_{2}$ nanotubes - Annealing effects on detailed morphology and structure, Eur. J. Inorg. Chem., 2010, 4351, (2010).

51. E. Gaul, Coloring titanium and related metals by electrochemical oxidation, J. Chem. Education, 70(3), 176 (1993).

52. M. V. Diamanti, S. Codeluppi, A. Cordioli, and MP. Pedeferri, Effect of therma oxidation on titanium oxides' characteristics, J. Experimental Nanoscience 4(4), 365 (2009) 